\title{
NOTAS SOBRE A PRESENÇA DA SÁTIA MENIPÉIA NAS MEMÓRIAS PÓSTUMAS E NO CONTO O SEGREDO DO BONZO
}

Eduardo Melo França ${ }^{1}$

Resumo: Este artigo se propõe a verificar, nas Memórias póstumas de Brás Cubas, a inserção do narrador digressivo e hipertrofiado, característico da sátira menipéia, mais especificamente do romance $A$ vida e as opiniões do cavalheiro Tristram Shandy. Também pretendemos mostrar que o conto $O$ segredo do bonzo pode ser lido como resultado de um diálogo entre Machado e Sterne acerca da Retórica e de suas possibilidade de manipulação e de estatuto de Verdade. Palavras-chave: Memórias póstumas de Brás Cubas, Sátira menipéia. A vida e as opiniões do cavalbeiro Tristram Shandy, Retórica, Narrador.

Abstract: This article aims to verify the presence in Memórias Póstumas de Bras Cubas of a digressive and hypertrophic narrator characteristic of Menippean satire, more specifically of The Life and Opinions of Tristram Shandy. It intends also to show that the short story 'O segredo do bonzo' can be viewed as an outcome of the dialogue between Machado and Sterne concerning rhetoric, its possibilities for manipulation and the rule of Truth.

Key words: Memórias Póstumas de Brás Cubas, Menippean satires, Life and Opinions of Tristam Shandy, Rhetoric, Narrator.

\section{MACHADO, UM HIATO LITERÁRIO}

O Brasil está presente na obra de Machado de tal forma que não podemos considerar inócua ou obsoleta qualquer tentativa de interpretação sociológica ou antropológica de sua obra. No entanto, devemos ter consciência de que seu projeto não era nacionalista ou de denúncia ideológica, mas estético. Tomando as palavras de Nabuco, seu palco era o mundo e não somente o Brasil. Seu sistema literário era o ocidental e não exclusivamente ou principalmente o nacional. A tocha que Machado recebeu (como quer chamar Antonio Candido), menos veio de Macedo, Manuel Antonio ou Alencar e mais de Sterne, Cervantes e Swift.

A crítica (e porque não também a teoria) literária brasileira vem sofrendo, durante seu percurso, um duro prejuízo decorrente de sua forte perspectiva sociológica. De forma geral, esse viés sociológico tem a mania de um nacionalismo literário, que põe em segundo plano aspectos fundamentais da retórica e da ficcionalidade da obra de Machado. Isto, sempre em prol do reconhecimento da nacionalidade de seus romances e contos (LIMA, 2006, p. 287). Quem pretende entender o nascimento do narrador das Memórias póstumas deve saber que essa obra não é fruto do contexto social brasileiro, mas do contexto literário ocidental.

1 Mestrando do Programa de Pós-Graduação em Letras da Universidade Federal de Pernambuco - UFPE. Endereço eletrônico: eduardomelofranca@hotmail.com 
Contudo, não sejamos injustos com os críticos literários. Os próprios escritores (ibero-americanos), de forma geral, durante o séc. XIX, também sofreram desse mesmo mal histórico-realista-nacionalista. Eles buscaram fazer um romance que Carlos Fuentes chama de "facundo". O século XIX ibero-americano foi fecundo e, sobretudo, "facundo". Isto é, permeado por um prosa que tinha como principal tema a conjunção de identidade nacional e história. O romance do século XIX pregava a análise social, a fotografia da terra, o retrato do caudilho e o monumento da língua (FUENTES, 2001, p. 8).

Eis então que surge Machado, um verdadeiro milagre literário. O escritor carioca pode ser considerado, como diz a canção de Caetano Veloso, "menos estrangeiro no lugar que no momento". Ou seja, ele é um hiato não somente na literatura brasileira ou ibero-americana, mas no século XIX. Foi ele quem resgatou a tradição legada por Cervantes e Sterne do tributo à ficção e à fantasia. E isso, segundo Fuentes, Machado conseguiu através de uma conciliação entre a tradição e a modernidade. Vale ressaltar que essa tradição apanhada por Machado não seria a novelesca brasileira ou portuguesa. Nesse momento, nem o Brasil, tampouco Portugal, poderiam atestar uma valiosa tradição novelesca (FUENTES, 2001, p. 10).

Boa parte da crítica parece fazer vista grossa ao fato do próprio Machado textualmente declarar no prólogo das Memórias póstumas de onde veio a forma do seu romance e a volubilidade de seu narrador. Permitam-me em tom de "brincadeira-séria" ser machadiano por um breve momento: Ora leitor, não sejas obtuso ou ignaro, não lembras que foi o próprio Machado quem assumiu ter escrito seu romance "a forma livre de um Sterne". E que Sterne, por sua vez, declarou que tomou a forma "do incomparável cavaleiro de La Mancha, a quem seja dito de passagem, eu amo mais a despeito de todas as sandices, do que ao maior herói da Antiguidade e por que mais longe eu iria fazer uma visita". Caro leitor, diria Machado, sejas mais atento. Releia as Memórias Póstumas e desta vez não esqueças do prólogo.

\section{SÁtiRa MENIPÉIA: FRAGMENTAÇõES E DigRESSÕES}

A sátira menipéia vem de uma tradição grega, dos diálogos socráticos, e mistura "temas especificamente filosóficos com assuntos de retórica e dialética, salpicados de hilaridade, para que o leitores menos informados pudessem ser atraídos à sua leitura por seu caráter jocoso" (SÁ REGO, 1989, p. 32). Diferente da tradição satírica romana, fundamentada na religião e na moral e que pretendia se contrapor e exterminar os vícios humanos, a menipéia, de caráter sério e cômico, mistura o popular, o erudito e o burlesco.

Essa tradição satírica é ao mesmo tempo cômica e trágica. É seria, mas desorganizada política e socialmente. Essa sátira apresenta uma enorme liberdade de invenção temática e filosófica. E o mais importante, como diz Bakhtin, ela cria 78

A Cor das Letras - UEFS, n. 8, 2007 
situações extraordinárias "para provocar e experimentar uma idéia filosófica" (1981, p. 81), ou seja, problematiza, põe à prova e principalmente satiriza as supostas "verdades" do mundo.

Não se pode ignorar que foi Sterne quem abriu as portas da sátira menipéia para Machado. Sendo uma mistura de gêneros literários e elementos cômicos e satíricos, essa tradição foi fundada pelo filósofo cínico Menipo de Gandara no séc III. Na antiguidade, seus principais representantes foram Varrão, Sêneca e Luciano de Samósata. Durante a Renascença e o Barroco, seus escritores mais importantes e que também prepararam a cama para o autor de Tristram Shandy foram Erasmo de Roterdam e Robert Burston (ROUANET, 2004).

Sterne ocupa um lugar especial entre os adeptos da sátira menipéia. Até o seu surgimento, os escritores pertencentes a essa tradição, em geral, se concentravam em poemas satíricos, comédias, tragédias, diálogos filosóficos e não no romance. Foi Sterne quem primeiro aplicou ao gênero romance o estilo dessa sátira (ROUANET, 2006, p. 320).

No prólogo da terceira edição das Memórias, Machado explica que essa:

Trata-se de uma obra difusa, na qual eu Brás Cubas, se adotei a forma livre de um Stern ou de um Xavier de Maistre, não sei se lhe meti algumas rabugens de pessimismo. Toda essa gente viajou: Xavier de Maistre, à roda do quarto, Garret na terra dele, Stern na terra dos outros. De Brás Cubas se pode talvez dizer que viajou à roda da sua vida (ASSIS, 1997, p. 512).

A auto-denúncia de intertextualidade exercida através do diálogo com Xavier de Maistre, Garret e Sterne, anuncia a adesão a uma forma especifica: à sátira menipéia - refuncionalizada no romance por Sterne. Segundo Rouanet, essa forma tem pelo menos quatro características:

(1) a presença enfática do narrador sublinhada, no texto, pelas palavras "eu Brás Cubas" (2) uma técnica livre de composição que confere ao texto um aspecto difuso, isto é, digressivo, fragmentário, não-discursivo; (3) a interpretação de riso e melancolia; (4) o lugar central conferido ao tempo (os paradoxos da cronologia) e ao espaço (viagens) (ROUANET, 2006, p. 320).

Todos esses autores citados por Machado, somados a Diderot com seu Jacques de la Fataliste, compartilham das mesmas características estruturais da sátira menipéia. Além de Rouanet, Merquior (em seu artigo Gênero e estilo nas Memórias póstumas de Brás Cubas) e Eugênio Gomes (em Espelho contra espelho), foram outros críticos que também perceberam a relação entre essa tradição satírica, a forma do romance de Sterne e as Memórias de Machado.

É explícita a tomada que Machado faz de Tristram como modelo. Ambos tratam o leitor e as regras estéticas de forma muito semelhante. Tristram é o exemplo máximo de um narrador volúvel. Sua atitude para com o leitor é desrespeitosa 
e arrogante. Assim como a falta de preocupação em manter uma linearidade narrativa. O leitor que o siga se for capaz e que perceba, quando for ofendido.

A primeira e mais marcante lição que Machado aprendeu com Sterne foi exatamente o apego pela fragmentação do texto e pela abundância de digressões. Ambos interpolam as narrativas com longas digressões que nos dois casos acabam tomando boa parte de seus romances. É justamente durante esses surtos de teorizações caprichosas que mais se evidencia a hipertrofia subjetiva e marcante desses narradores. A partir delas tomamos conhecimento das opiniões de Tristram e das memórias de Brás, além da melancolia e do humor amargo de ambos os narradores.

Em Tristram Shandy, boa parte das digressões diz respeito às opiniões de Tristram. É através de comentários e opiniões ora anedóticos, ora pretensamente filosóficos, que Sterne ressalta a hipertrofia do seu narrador. Quando desejando inserir na narrativa uma digressão, Sterne lança mão de um artifício quase imagético: ele esquece seus personagens de modo que parecem ficar em "pausa", enquanto discorre longamente sobre qualquer outra coisa. Exemplos não faltam. Vejamos o que acontece com o tio Boby. Exatamente quando sacudia as cinzas do seu cachimbo ele é posto em "pausa" e assim permanece desde o capítulo XXI do livro I até o capítulo VI do livro II. O objetivo dessa "pausa"? Quarenta páginas de digressões sem nexo ou utilidade. Puro capricho do narrador. Contudo, são essas inúmeras interrupções que dão charme e caracterizam o ritmo peculiar do romance.

Outro exemplo é a parteira que após ter sido mencionada, permanece durante seis capítulos esquecida pelo narrador. Quando se lembra da pobre coitada, com remorso, comenta o narrador: "Faz tanto tempo que o leitor desta obra rapsódica se viu afastado da parteira, que é mais do que hora de mencioná-la novamente" (STERNE, 1998, p. 71).

Há também as digressões que problematizam materiais já prontos, como um texto em francês antigo de teólogos da Sorbonne sobre a legitimidade do batismo de bebês não nascidos; um sermão lido pelo cabo Trim, atribuído ao pároco Yorck; e o texto latino de uma maldição, escrito pelo Bispo Ernullphus.

As estórias isoladas que correm paralelas à narrativa principal caracterizam o terceiro tipo de digressão. Um exemplo é o conto atribuído ao Dr. Slawkenergius, no qual ele ressalta a importância dos narizes grandes. Há também a pequena estória do que acontece na corte da rainha Navarra, que trata de bigodes e insinua obscenidades. Além dessas e outras estórias isoladas espalhadas por todo o romance, podemos distinguir dois ciclos narrativos: um sobre a vida do tio Boby e outro centrado nas estórias contadas pelo seu criado Trim (ROUANET, 2006, p. 325).

Esses três tipos de digressão também estão nas Memórias póstumas de Brás Cubas. Coincidência? Creio que não. Prefiro chamar de intertextualidade. Ou seja, ambos os autores fazem parte da mesma tradição literária, que por sua vez é mar80

A Cor das Letras - UEFS, n. 8, 2007 
cada pela narrativa digressiva. Pois bem, para que não sejamos acusados de parcialidade ou de escassez de evidências, apontemos onde podemos encontrar nas $\mathrm{Me}$ mórias esse material digressivo.

O primeiro tipo, e como mencionei o mais marcante, diz respeito à presença impertinente das opiniões hipertrofiadas de Brás. Entre essas digressões opinativas temos as que refletem sobre as botas apertadas, sobre a ponta do nariz, as borboletas pretas e a teoria da equivalência das janelas.

As digressões compostas por materiais já prontos aparecem nos aforismos do capítulo CXIX e no epitáfio do capítulo CXXV, que substitui a descrição da morte da noiva presuntiva de Brás, Nhá-Loló.

Quanto ao terceiro tipo de digressão - as narrativas paralelas - a principal delas é a estória de Quincas Borba. Mas, também não faltam pequenas narrativas e capítulos praticamente independentes da narrativa principal que mais se estruturam como contos e apólogos, tais como o capítulo do Almocrve.

Machado fragmentou seu romance ao modo shandiano, isto é, a partir das digressões. Rouanet nota que ambas as obras apresentam narrativas principais, que por sua vez são constantemente interrompidas por digressões. Essas digressões, então são interrompidas pela narrativa principal que é retomada e agora também interrompida por novas digressões. Cada interrupção do fluxo narrativo (ou digressivo) gera dois outros fragmentos. Daí a infinidade de fragmentos que compõem o texto.

E se ainda há quem insista em desprezar essas evidências que vinculam a volubilidade do narrador machadiano ao modelo shandiano e conseqüentemente à sátira menipéia, insisto que façamos uma pequena retrospectiva dos nossos argumentos. Partimos primeiro das palavras de Machado. No prólogo das Memórias póstumas ele mesmo anuncia - até para os que tentarão ignorar - sua descendência literária e de onde se origina a volubilidade da narrativa de Brás. Ele assume que Maistre, Garret e Sterne são seus modelos e que "Há na alma desse livro, por mais risonho que pareça, um sentimento amargo e áspero, que está longe de vir dos seus modelos" (ASSIS, 1997, p. 512, grifo nosso). Segundo ponto, a relação sádica, desabusada e desrespeitosa com a qual tanto Machado quanto Sterne tratam o leitor. Terceiro, a presença evidente dos mesmos três processos digressivos e por conseqüência a fragmentação infinita da narrativa e das digressões de Brás e Tristram.

O texto de Machado, como mais adiante refletiremos, se insere e ao mesmo tempo refuncionaliza e amplia o conceito de forma que ele e Sterne herdam da sátira menipéia. Não finjamos não ver sua filiação, afinal, como ele mesmo diz, $A s$ memórias póstumas de Brás Cubas em relação aos seus interlocutores "é taça que pode ter lavores de igual escola, mas leva outro vinho. Não digo mais para não entrar na crítica de um defunto, que se pintou a si e a outros, conforme lhe pareceu melhor e mais certo" (ASSIS, 1997, p. 512, grifo nosso). 
Nas palavras do próprio Machado, a arte é a única coisa que tem seu fim em si mesma. Ela não tem obrigação para com qualquer coisa, nem com história, nacionalidade, legitimação ou contestação do que quer que seja. Sua única obrigação é para com o leitor. Também por isso, As memórias póstumas não tem como referente uma percepção realista da sociedade brasileira e de seu descompasso ideológico, mas sim a retórica e suas estratégias. Nesse sentido, o livro poderia sem muito esforço e para a alegria dos pós-modernos, se encaixar no conceito de metaficção.

As memórias, assim como Don Quixote (também seu primo), Trsitram Shandy e Jacques le Fataliste "são obras em que o processo de composição está integrado ao produto estético, que por sua vez é explicitamente apresentado ao mesmo tempo como arte e como (imitação da) vida" (MUECKE, 1995, p. 41). Sterne e Machado não só esclarecem o processo, os elementos e os artifícios retóricos utilizados na construção de seus romances, como também os incluem numa ciranda digressiva, na qual nada se salva de alguma ironia. Em Machado o processo (irônico) de autoesclarecimento ocorre desde o prólogo, onde através da menção de seus modelos sugere como conseguiu finalmente lapidar seu herói e sua narrativa.

Brás se autocongratula ressaltando a maestria com a qual maneja seus "processos extraordinários" (ASSIS, 1997, p. 513). Elogia seu tom "supinamente filosófico" (MP. IV. 516) e o método que empreendeu a fim de dar forma ao romance: "E vejam que destreza, com que arte faço eu a maior transição deste livro [...] De modo que o livro fica assim com todas as vantagens do método, sem a rigidez do método" (ASSIS, 1997, p. 526). Ao mesmo tempo em que Brás se elogia, também é capaz de se autocriticar. Diz que se em alguns momentos seu livro apresenta a sabedoria que fugiu a Aristóteles, em outros apresenta alguns capítulos tristes ou inúteis. Revela que enquanto escritor não espera que sua obra chegue a ser lida por dez pessoas. Renega o enfático: "Ui! Lá me ia a pena a escorregar para o enfático" (ASSIS, 1997, p. 546) e a prolixidade: "as vezes esqueço-me a escrever, e a pena vai comendo papel, com grave prejuízo meu, que sou o autor” (ASSIS, 1997, p. 544).

\section{DA RETÓRICA À RETÓRICA}

Sabe-se que o pensamento de Locke foi fundamental na concepção sterniana de narrativa não linear. Para o filósofo inglês o tempo é uma idéia e a sucessão dessas idéias é o que faz o tempo ter duração. Duração essa que se estabelece sobre a reflexão consecutiva de varias idéias e de suas conseqüências. A distância entre essas idéias e reflexões é de um espaço incerto. Por isso, para Locke a passagem do tempo é absolutamente subjetiva, podendo ser rápida, lenta, sinuosa ou objetiva, dependendo apenas de nosso estado de espírito. Sterne tomou como munição as idéias de Locke e as utilizou para atacar a concepção de romance apresentada por Fielding e Richardson. Enquanto esses dois últimos autores se ajustavam ao princípio fundamental da imitation, pelo seu desenvolvimento linear da história, Sterne 82 A Cor das Letras - UEFS, n. 8, 2007 
escreve um romance tomando como artifício narrativo o tempo psicológico de Locke (LIMA, 1981, p. 59).

A adesão ao tempo psicológico e às inúmeras digressões e fragmentações fazem das Memórias e de Tristram um zigue-zague continuo, através do qual o leitor nunca saberá qual o destino certo. Elaborada de forma consciente, Machado, ou melhor, Brás, tem orgulho dessa narrativa em zigue-zague. Seu livro e seu estilo são "como ébrios, guinam à direita e à esquerda, andam e param, resmungam, urram, gargalham, ameaçam o céu, escorregam e caem” (ASSIS, 1997, p. 583).

A propósito dessa citação, Enylton de Sá Rego, em seu livro O calundu e a panacéia, cita o estudo The Satire of Seneca on the Apotheosis of Claudius, realizado por Allan P. Ball. Notemos a inegável semelhança existente entre a análise que Ball faz da narrativa menipéia e a descrição - logo acima citada - que o próprio Brás faz de sua narrativa ébria. Comenta Ball: "[...] a essência da sátira menipéia é exatamente o seu andamento variado e desenfreado, andando, correndo, tropeçando, de vez em quando se permitindo até uma cabriola" (apud SÁ REGO, 1989, p. 42).

No entanto, Machado não foi um simples reprodutor da forma shandiana. Se o método é comum aos dois autores, a função não. Em Sterne, as digressões (inclusive as mais disparatadas), o tempo psicológico, a hipertrofia subjetiva do narrador, suas opiniões e a narrativa em zigue-zague, são armas utilizadas para se contrapor ao deísmo escolástico e ao romance de linha substancialista (LIMA, 1981, p. 64). Uma das grandes contribuições de Sterne foi denunciar a impossibilidade da linguagem fecundar a realidade. $\mathrm{O}$ escritor Irlandês não só é responsável pela refuncionalização da sátira menipéia (aplicada ao romance), mas também de um redirecionamento do romance. Com Tristram, o gênero é deslocado do eixo da existência substancial, para o relacional. Por conseguinte, deixa de ser legitimado enquanto gênero histórico e encontra seu lugar no campo da imaginação. No momento em que o romance deixa de ser reflexo da realidade e tentativa de reprodução do Ser, ele, juntamente com a emergência do sujeito poético, efetua a passagem do primado da natureza para o da imaginação (LIMA, 1981, p. 62-63).

Toda fluidez do romance de Sterne tinha como objetivo principal satirizar o mundo medieval dominado pela retórica pré-racionalista, na qual seus pensadores pressupunham explicações pretensamente racionais e objetivas, mas não verificáveis e absolutamente contestáveis. Sterne instalou, ou melhor, percebeu o hiato entre a linguagem e o mundo. Percebeu que o mundo que descrevemos não é o mundo no qual vivemos, mas um mundo literalmente transcrito e não transcrito literalmente. Tomemos como exemplo o episódio no qual tio Boby comunica a Walter a morte de seu filho mais velho. Embriagado pelas palavras, mas sem muito entendê-las, o pai não compreende o que lhe é dito, contudo, diante da confiança nas palavras e em quem as emite, ele cega e inocentemente as aceita como verdade. 
O alvo de Sterne era fixo, certo, mas contingencial. Ele criticava através da sátira um modo específico de retórica: a pré-racionalista e conseqüentemente no campo literário o romance linear. Com Machado a estória era outra (e mais ampla). Sua intenção era menos um ataque direcionado a alguma retórica em particular e mais uma problematização das possibilidades e estratégias de poder da Retórica. Enquanto Sterne critica uma retórica que se propõe ordenadora e classificadora do mundo, Machado mostra-se consciente dessa proposta ordenadora ser apenas uma entre as várias aplicações de manipulação dos discursos e do conceito de verdade. Machado prefere rir e, mais do que denunciar a retórica pré-racionalista, satirizar as diversas possibilidades de construções discursivas que supostamente adquirem o status de verdade.

\section{O ESTATUTO DA VERDADE EM O SEGREDO DO BONZO}

O interesse de Machado pelo processo retórico, suas armadilhas e possibilidades de verossimilhança extrapolam as páginas das Memórias. Em O segredo do bonzo, o estatuto de verdade e o poder da palavra diante da realidade são problematizados a tal ponto que Machado ao mesmo tempo em que demonstra a impossibilidade da realidade e da linguagem se fundirem naturalmente, escancara as estratégias retóricas e discursivas utilizadas pelos saberes filosóficos e científicos.

Além de $O$ segredo do bonzo, Teoria do medalhão é exemplar na sua capacidade de problematizar o discurso manipulador de poder. Contudo, por ora, nos atenhamos a $O$ segredo do bonzo, uma vez que ele problematiza a mesma matéria que nós, i. e., o valor do discurso enquanto verdade, a cientificidade e o papel da retórica nesses processos.

Vale salientar que tal como no prólogo das Memórias, também no dos Papéis avulsos Machado nos dá uma valiosa dica da natureza dos contos que compõem essa antologia. Esses contos, nas suas palavras, são como "pessoas de uma só família, que a obrigação do pai fez sentar à própria mesa”. São da mesma família, pois todos, do mesmo modo que As memórias, fazem parte de um mesmo projeto estético-literário. Todos têm como referente a retórica, a palavra e o discurso ficcional.

O que primeiro devemos observar em $\mathrm{O}$ segredo do bonzo é que os três episódios nos quais os supostos sábios declaram suas importantes descobertas para a humanidade se enquadram perfeitamente no eixo temático satirizado por Sterne. Os discursos utilizados pelos três oradores na declaração da importância de suas descobertas são exemplos caricatos, mas não vulgares, de supostos saberes préracionalistas. Isto é, explicações de teor científico, objetivo e que se propõem a decifrar e ordenar o mundo.

Com um só conto, Machado resolve dois problemas de uma só vez. Ao retratar os três oradores com suas retóricas ordenadoras e pretensamente científicas, satiriza a tentativa de alguns cientistas em ignorar o espaço existente entre a reali84

A Cor das Letras - UEFS, n. 8, 2007 
dade e as palavras. Os discursos dos três oradores de Fucheu encaixam-se no mesmo tipo de retórica satirizada por Sterne no episódio no qual Tio Toby comunica a Walter Shandy a morte de seu filho mais velho, Boby. De um lado, temos os habitantes de Fucheu que aceitam como verdade formulações teóricas e um discurso que utiliza como principal recurso retórico o pensamento pretensamente cientifico. Do outro lado, em Tristram Shandy, temos Walter Sahndy que toma como realidade uma retórica vazia, falsamente erudita e que absurdamente transpõe o metafórico para o literal. Ou seja, se o valor e a legitimação de um discurso não é algo em si, mas que necessariamente precisa passar pela aceitação de um outro, a retórica inevitavelmente assume um papel fundamental de persuasão, principalmente na manipulação de argumentos e na construção de uma suposta cientificidade ou erudição.

Desta vez, façamos não como Machado, mas como Sterne. Interrompamos a narrativa principal deste texto para uma pequena digressão. Certamente todos somos capazes de notar a significativa relação entre $\mathrm{O}$ segredo do bonzo e o Tristram Shandy de Sterne. Além da retomada da satirização da retórica vazia e pretensamente racionalista, não se pode fingir não ver que o nariz metafísico machadiano é uma clara referência à teoria do Dr. Slawkenbergius, do Tristram Shandy, que afirma a importância dos narizes grandes na vida do indivíduo.

De fato, Machado utilizou o mesmo objeto que Sterne para alcançar o mesmo efeito de ironia através do despropósito. Entretanto, o "nariz" de Machado é diferente. O Dr. Slawkenbergius, enquanto criador da teoria da importância do nariz grande, mostra-se tão imerso e perdido no mar da retórica pré-racionalista, quanto os que nessa teoria acreditam. Ele é o representante da corrente satirizada por Sterne: os pré-racionalistas, escritores medievais de tratados que pretendiam explicar o mundo. Diogo Meireles, em $O$ segredo do bonzo, é exatamente o oposto. Ou melhor, é a sátira da sátira. Diogo Meireles, na verdade, é a sátira sterniana revirada ao avesso e cinicamente consciente da vacuidade de sua própria retórica.

Enquanto Dr. Slawkenbergius está preso nesse sistema e por isso não é capaz de perceber o disparate da sua teoria, Digo Meireles é mais um exemplo da intenção machadiana de satirizar a Retórica, expondo ironicamente seus estratagemas e o lugar que seus recursos podem ocupar na construção e legitimação de um determinado discurso. Diferente do Dr. Slawkenbergius, o viajante machadiano não está enfeitiçado pelo canto da retórica. Ele a utiliza, não porque é cego ou iludido, mas porque é cínico. Ele é consciente da estratégia que utiliza.

Essa sutil diferença é um grande exemplo do passo adiante dado por Machado em relação a Sterne. Com a criação desse nariz metafísico, ele anuncia que sua preocupação não é a desconstrução desse ou daquele discurso pretensamente racionalista, mas a satirização da Retórica e de suas possibilidades. Com já afirmamos no início do texto, uma das características mais marcantes da sátira menipéia e 
que pode ser observada em $O$ segredo do bonzo, é a criação situações extraordinárias "para provocar e experimentar uma idéia filosófica" (1981, p. 81). Isto é, um dos objetivos da sátira menipéia é satirizar discursos metafísicos (em muitos momentos religiosos) e "verdades" (pretensamente racionalistas) e supostamente estabelecidas sobre o homem e o mundo.

O nariz, para Machado, como também para Sterne, pode ter tanta importância na vida de uma pessoa, quanto simplesmente ser uma entidade metafísica, basta apenas que se acredite nisso. Podemos até imaginar Brás ou Tristram interpelando o leitor, chamando-o de obtuso e dizendo: o que seria um nariz, senão qualquer coisa que quiséssemos!

\section{O Riso e A MElancolia Em Machado e Sterne}

Outro ponto que denuncia a herança shandiana no narrador machadiano é a relação entre o riso e a melancolia. Certa vez, respondendo qual sua definição de humor, disse Bernard Shaw: "O que quer que lhe faça rir. Mas o de melhor qualidade provoca uma lágrima junto com o riso" (SHAW, 1996, p. 321). Confesso que não poderia encontrar melhor citação para definir como Machado e Sterne perceberam o pingo de melancolia que sempre há no riso.

Sterne acredita que o riso é o remédio para todas as melancolias. Seja na passagem do tempo, na morte e no presente ingrato que é a vida, em tudo há melancolia. A risada no canto da boca, sempre que teorizando sobre qualquer um desses temas é a solução que ele encontrou para se salvar dessa flor amarela que corrói o espírito.

Em Machado o que se observa é ago um tanto diferente. Se em Sterne o riso é a possibilidade de se salvar da melancolia, em Machado o próprio riso é utilizado para debochar de qualquer tentativa de se salvar desse mal. Machado admite que a melancolia e a tragicidade da vida são condições inevitáveis do ser humano e que qualquer tentativa de se salvar desta condição acaba sendo ridicularizada com um sorriso amarelo. O exemplo maior de como o ridículo e a risada maliciosa estão sempre apontados para qualquer tentativa de fuga da melancolia, foi Brás ter morrido por conta de um reles vento encanado, exatamente quando trabalhava na confecção de um emplasto que salvaria a humanidade da "hipocondria".

O riso que emerge através da ironia, não é simplesmente um recurso formal, mas um modo de Machado ver e estar no mundo. Em tudo ele admite uma leitura irônica. Inclusive na tentativa ridícula do indivíduo, um ser finito que luta para compreender, teorizar e dar unidade a uma realidade infinita, portanto incompreensível (MUECKE, 1995, p. 39).

Sobre isso, outro autor vale ser mencionado: Pascal. A miséria humana e a melancolia em Sterne não perdem a esperança de serem aplacadas pelo riso. Em Pascal, a dor humana é a prova e o caminho para a aceitação de Deus e do Cristia86

A Cor das Letras - UEFS, n. 8, 2007 
nismo. Para Machado, essa mesma dor, contradição e ironia na qual estamos imersos é a própria condição humana.

A ironia em Machado é infinitamente mais ampla do que em Sterne. Ele chega a problematizar o próprio estatuto da ironia. As contradições dos comportamentos humanos e do constante misto entre riso e melancolia, ou como diz Shaw, entre o que faz rir e chorar, presentes em sua obra, nos faz entender que a ironia "é a análise [na medida em que opõe à síntese] da tese e da antítese" (MUECKE, 1995, p. 40). Essa perspectiva de ironia, quando aplicada à obra machadiana, irradia tanto sua forma, quanto sua concepção de homem. Acerca da forma, entende-se que o mesmo discurso gera sua afirmação e trás em si sua contradição e negação. Isto é, todo discurso é manipulável e, como diz Rorty, qualquer status de verdade nada mais é do que um elogio dado a uma idéia bem argumentada.

Ao mesmo tempo em que As memórias póstumas de Brás Cubas é um brinde ao estatuto ficcional, também é uma deliciosa exibição de como se pode brincar com as palavras. Machado escreveu uma obra transparente, na qual desde o início sua filiação é anunciada e seus estratagemas retóricos se auto-ironizam. E se é possível estabelecer alguma relação entre a forma narrativa e algum referente que não seja a própria Retórica, essa não diria respeito a qualquer sociedade ou descompasso ideológico, mas à volubilidade do espírito humano e a igualmente volúvel e caprichosa narrativa de Brás.

Sterne e Machado, através de suas narrativas, nos transmitiram a constante mutabilidade do espírito humano. Machado leu Montaigne e certamente o ensaio Da incoerência de nossas ações não the passou em branco. Ambos os autores acreditavam na indefinição psicológica do indivíduo, na contradição inevitável das nossas ações e na impossibilidade de nos mantermos os mesmos por um simples segundo. Por isso, ao lermos Montaigne afirmando que "quem se examina de perto raramente se vê duas vezes no mesmo estado” (MONTAIGNE, 1987, p. 100), sabemos que tanto isso poderia ter sido dito por Brás e Tristram, quanto retratado através das narrativas digressivas e volúveis d'As memórias póstumas de Brás Cubas e d'A vida e opiniões do cavalheiro Tristram Shandy. 


\section{REFERÊNCIAS}

ASSIS, Machado de. Memórias póstumas de Brás Cubas. In Obras completas, v. 1. Rio de Janeiro: Nova Aguilar, 1997, p.511-639.

ASSIS, Machado de. O segredo do Bonzo. In Obras completas, v. 2. Rio de Janeiro: Nova Aguilar, 1997, p. 323-328.

ASSIS, Machado de. Teoria do medalhão. In Obras completas, v. 2. Rio de Janeiro: Nova Aguilar, 1997, p. 288-295.

BAKHTIN, Mikhail. Problemas da poética de Dostoievski. Rio de Janeiro: Forense-Universitária, 1981.

FUENTES, Carlos. Machado de La Mancha. México D. F.: Fondo de Cultura Econômica, 2001.

GOMES, Eugênio. Espelho contra espelho. São Paulo: Ipê, 1949.

LIMA, Luiz Costa. História. Ficção. Literatura. São Paulo: Cia. das Letras, 2006.

LIMA, Luiz Costa. Dispersa demanda. Rio de janeiro: Francisco Alves, 1981.

MERQUIOR, José Guilherme. Gênero e estilo das Memórias póstumas de Brás Cubas. Colóquio Letras, Lisboa, n. 8, p. 12-20, 1972. [A Problematic Vision. Review, New York, n. 16, p. 45-51, 1975].

MONTAIGNE, Michel Eyquem de. Da incoerência de nossas ações. In Ensaios, v. 2. Brasília: Hucitec; Ed. UNB, 1987, p. 97-102.

MUECKE, D. C. Ironia e o irônico. São Paulo: Perspectiva, 1995.

ROUANET, Sergio Paulo. Tempo e espaço na forma shandiana: Sterne e Machado de Assis. Estud. Av., São Paulo, v. 18, n. 51, 2004. Disponível em: <http://www.scielo.br/ scielo.php?script $=$ sci_arttext\&pid $=$ S0103-40142004000200021\&lng $=$ en\&nrm=iso $>$. Acesso em: 8 jan. 2007. Doi: 10.1590/S0103-40142004000200021.

ROUANET, Sergio Paulo. O mal-estar na modernidade. São Paulo: Cia. das Letras, 1993.

ROUANET, Sergio Paulo. A forma shandiana: Laurence Sterne e Machado de Assis. In: Teresa: Revista de Literatura Brasileira, n. 6/7. São Paulo: Ed. 34; Imprensa Oficial, 2006, p. 318-339.

SÁ REGO, Enylton José de. O calundu e a panacéia: Machado de Assis, a sátira menipéia e a tradição luciânica. Rio de Janeiro: Forense Universitária, 1989.

SHAW, B. O teatro das idéias. São Paulo: Cia. das Letras, 1996.

STERNE, Laurence. A vida e opiniões do cavalheiro Tristram Shandy. São Paulo: Cia. das Letras, 1998. 